in Case 2 were more rapid and extensive and subsequently produced serious loss of visual field. These field changes were of two distinct types: (1) an insidious progressive loss corresponding with gradually increasing ischaemia in the retinal territory supplied by the diseased vessel, and (2) additional acute absolute loss produced by successive involvement and occlusion of the arteriolar branch of this vessel with resultant retinal infarcts. Vascular changes described as "sheathing" occurring after cholesterol emboli were noted by Balla et al. (1964). The same authors mention that this reaction tended to occur in the larger retinal arteries, and the present observations seem to bear this out; that is to say, the mural changes were seen in small retinal arteries rather than in arterioles. This observation also broadly agrees with the findings of the authors mentioned above, who studied necropsy material from a variety of organs, excluding the eye.

The origin of cholesterol emboli in the present cases has not been determined. The ipsilateral carotid systems showed no filling defects distal to the site of angiography puncture. The possibility of atheroma proximal to this point has not been eliminated in these two patients, cardiac disease was not evident clinically, electrocardiograms were normal, and straight $x$-ray films of the mediastina did not reveal calcification in the heart or the great vessels. It is of course possible that erosion of atheromatous plaques in the internal carotid or other great vessels may occur in cases showing no angiographic defect or $x$-ray opacities due to calcification.

Transient unilateral loss of vision which is not obviously due to carotid stenosis (that is, its occurrence in patients in whom the difference in ophthalmodynamometry readings on the two sides is repeatedly less than $15 \%$ ) has been categorized from an aetiological standpoint by Cogan (1961). In one group he found bright refractile plaques in the ipsilateral retinal arteries, and transient loss of vision in these cases was thought to be due to local arteriosclerotic change. It now seems likely that these cases should be grouped with the present Cases 1 and 2, in which the bright plaques have been identified as cholesterol emboli and which have been demarcated from those with angiographically demonstrable occlusive carotid disease.

\section{Summary}

Two patients presenting with transient monocular loss of vision were found to have cholesterol embolization of the ips1lateral retinal arteries. There was no angiographic evidence of ipsilateral carotid occlusive disease in either patient.

A review of the literature equating bright plaques in retinal arteries with cholesterol emboli is given. Present observations have provided further evidence in favour of the embolic nature of these plaques.

Serial fundus photographs record progressive sclerotic changes after the impaction of cholesterol emboli in what were previously apparently healthy retinal arteries.

In Case 1 these changes were slow in evolving and were not associated with retinal ischaemia one and a half years later. In Case 2 similar but more rapid vascular sclerosis produced chronic retinal ischaemia in the territory of the affected artery with superadded successive acute infarction. Visual-field studies have closely corroborated these findings.

It is a pleasure to acknowledge the assistance given by Dr. Keith Brammar, who was responsible for taking the fundus photographs. We are also grateful to Dr. J. P. P. Bradshaw, consultant neurologist at the Royal Hospital, Sheffield, and to Professor F. Jacoby, Director of Subdepartment of Histology, University of Cardiff, South Wales, for their valuable comments during the preparation of the manuscript.

\section{REFERENCES}

Balla, J. I., Howat, J M. L., and Walton, J. N. (1964). F. Neurol. Neura surg. Psychiat.; 27, 144.

Cogan, D. G. (1961). Arch. Ophthal., 66, 180.

David, N. J., Klintworth, G. K., Friedberg, S. J., and Dillon, M. (1963). Neurology (Minneap.), 13, 708.

Fisher, M. (1952). Arch. Ophthal., 47, 167.

Fisher, M. (1952). Arch. Ophthal., 47, 167.

Flory, C. M. (1945). Amer. F. Path., 21, 549.

Hollenhorst, R. W. (1961). Trans. Amer. ophthal. Soc., 59, 252. Hollenhorst, R. W. (1962). Trans. Amer. Acad. Ophthal. Otolaryng., 66, 166.

- Lensink, E. R., and Whisnant, J. P. (1962). Trans. Amer. ophthal Soc., 60, 316 .

McBrien, D. J., Bradley, R. D., and Ashton, N. (1963). Lancet, 1, 697

Russell, R. W. R. (1961). Ibid., 2, 1422.

Sayre, G. P., and Campbell, D. C. (1959). Arch. intern. Med., 103, 799.

\title{
Correlation of Chromosome Counts with Histological Appearances and Prognosis in Transitional-cell Carcinoma of Bladder
}

\author{
DAVID LAMB,* M.B., B.S., B.SC.
}

Brit. sned. 7., 1967, 1, 273-277

The study of chromosome changes in malignant tumours has become an important aspect of cancer research in recent years. With the exception of some leukaemias, all primary human malignant tumours examined without prior cell culture have had abnormal chromosome sets (Spriggs, 1964), but little correlation has emerged between the chromosome changes and the histological appearances.

Atkin and Richards (1962) and Atkin (1964), using microspectrophotometric measurements of nuclear deoxyribose nucleic acid (D.N.A.), have shown that high ploidy in squamous carcinoma of the cervix is associated with a good prognosis, but not with any particular histological appearance. In adenocarcinomas of the uterine body, however, high ploidy was found to be associated with a poorly differentiated histological pattern but not with prognosis.

- Research Assistant, Institute of Diseases of the Chest, London.
In none of the large published series of chromosome studies on human material (Makino et al., 1959, 1964 ; Ishihara et al., 1963 ; Spriggs et al., 1962b ; Hauschka, 1963) have these findings been confirmed or similar findings reported for tumour at other sites.

Shigematsu (1965) has studied the chromosomes in a series of transitional-cell carcinomas of the bladder. He found a relation between the levels of chromosome count and the histological picture.

It was decided to study the relation of chromosome number to the pathological findings in a series of transitional-cell carcinomas of the bladder. Transitional-cell carcinoma of the bladder was chosen because there is a well-recognized relation between the histological grade of malignancy and the presence and depth of invasion, and between these two factors and prognosis. 


\section{Materials and Methods}

Tissue was collected from 40 patients with bladder tumours undergoing open operation. Twenty-nine of these cases gave chromosomal preparations adequate for counting and form the basis of this study. Two tumours were obtained from one case (see below). None of these cases had had previous radiotherapy. Each tumour specimen was divided in two; one piece was fixed in formol-saline for histology, and chromosome preparations were made from the other. Care was taken that the part examined histologically was closely adjacent to the area used for making chromosome preparations.

Chromosome Preparation.-A cell suspension was made in T.C. medium " 199 " by teasing the tumour apart and gently stroking the cells into suspension. The cell suspension was treated with demecolcine (Colcemid) $(0.5-1 \mu \mathrm{g} . / \mathrm{ml}$.) for one to two hours at $37^{\circ} \mathrm{C}$. This suspension was then diluted 4 to 1 with distilled water at $37^{\circ} \mathrm{C}$. After 25 minutes the suspension was centrifuged and the button of cells fixed in 4:1 methanol-acetic-acid. Chromosome spreads were made by dropping the cell suspension on to slides previously stored in $50 \%$ glacial acetic acid at $4^{\circ} \mathrm{C}$. and drying over a low flame. Slides were stained in $1 \%$ aqueous brilliant cresyl violet and mounted in Canada balsam.

Chromosome Counting. - The slides were scanned and every chromosome spread was examined. Spreads which had much crowding or overlapping of chromosomes were not counted. However, in such cells, if the chromosome number seemed to differ from the general pattern-for example, an apparent tetraploid cell in a case which otherwise had a diploid modethis was noted.

\section{Histological Grading}

The histological grading of the tumours was based on the Institute of Urology's classification for bladder tumours (Dukes, 1959 ; Pugh, 1959) in which the tumours are first divided into groups-(i) papillary, (ii) papillary and solid (infiltrating), and (iii) solid (infiltrating)-depending on the overall pattern of growth. Each group is then further subdivided on histological criteria into: (1) papilloma, (2) well-differentiated transitionalcell carcinoma, and (3) poorly differentiated transitional-cell carcinoma. The term papilloma is limited to a papillary growth covered with epithelium indistinguishable from normal bladder epithelium-that is, less than five cells thick and showing no evidence of invasion. A "well-differentiated transitional-cell carcinoma" still retains sufficient differentiation to reveal its origin from transitional-cell epithelium. "Poorly differentiated transitional-cell carcinoma" has, at at least in part of the tumour, lost any resemblance to bladder epithelium.

For the purpose of this paper the group "well-differentiated transitional-cell carcinoma" is further subdivided into two groups: well-differentiated carcinoma and moderately welldifferentiated carcinoma. Well-differentiated transitional-cell carcinoma has recognizable transitional epithelium more than five cells thick, with minimal loss of cell regularity and with minimal nuclear changes. Moderately differentiated transitionalcell carcinoma still resembles transitional epithelium but shows greater loss of cell regularity and has more marked nuclear pleomorphism.

The presence and extent of invasion has been assessed in each case by the International Urological Association grading : in situ; $\mathrm{T} 1$, submucosal invasion, including any penetration of basement membrane such as may occur in the fronds of papillary growth; T2, superficial muscular invasion; and $\mathrm{T} 3$, deep muscle invasion or through bladder wall, and including lymph-node spread.
Results

Of the 30 tumours studied none were simple papillomata. Five were well-differentiated transitional-cell carcinomas, seven moderately differentiated, and 18 poorly differentiated. In one patient two parts of the same tumour were examined: the histological appearances were so different that these were graded separately and counted as two tumours (Cases 21 and 22).

Chromosome Counts.-Altogether over 700 chromosome spreads were counted from the 30 tumours, the number for individual tumours varying from 5 to 51 . The results are summarized in the Table and Figs. 1 to 4 . Because of a low mitotic index in some of the well-differentiated cases very few spreads could be counted.

Well-differentiated Tumours (see Table and Fig. 1).-All five tumours have chromosome counts around the diploid value, three having modal values at 46 . The range of counts is narrow, and a high percentage of counts lie at the modal value - the mean proportion of counts at the modal value for the

\begin{tabular}{|c|c|c|c|c|c|c|}
\hline \multirow{2}{*}{$\begin{array}{l} \\
\text { Case } \\
\text { No. }\end{array}$} & \multicolumn{6}{|c|}{ Summary of Findings } \\
\hline & $\begin{array}{l}\text { No. of } \\
\text { Cells } \\
\text { Counted }\end{array}$ & Invasion & Modal No. & $\begin{array}{l}\% \text { Cells } \\
\text { at Modal } \\
\text { No. }\end{array}$ & $\begin{array}{l}\text { Range of } \\
\text { Cell } \\
\text { Counts }\end{array}$ & $\begin{array}{l}\text { No. of } \\
\text { Cells with } \\
\text { Recogniz- } \\
\text { ably } \\
\text { Abnormal } \\
\text { Chromo- } \\
\text { somes }\end{array}$ \\
\hline \multicolumn{7}{|c|}{ Well-differentiated Cases } \\
\hline $\begin{array}{l}12 \\
13 \\
16 \\
17 \\
25\end{array}$ & $\begin{array}{r}12 \\
10 \\
5 \\
23 \\
26\end{array}$ & $\begin{array}{c}\text { In situ } \\
", ", \\
" 1, " \\
\text { In situ }\end{array}$ & $\begin{array}{c}46 \\
46 \\
46 \\
47-48 \\
45\end{array}$ & $\begin{array}{l}85 \\
60 \\
60 \\
43 \\
19.5\end{array}$ & $\begin{array}{l}44-46 \\
44-48 \\
45-46 \\
42-50 \\
32-49\end{array}$ & $\begin{array}{l}0 \\
0 \\
0 \\
0 \\
11\end{array}$ \\
\hline \multicolumn{7}{|c|}{ Moderately Well-differentiated Cases } \\
\hline $\begin{array}{r}7 \\
14 \\
15 \\
19 \\
21 \\
24 \\
29\end{array}$ & $\begin{array}{r}8 \\
16 \\
23 \\
25 \\
13 \\
28 \\
25\end{array}$ & $\begin{array}{c}\text { In situ } \\
" \text { "” } \\
1 \\
1 \\
\text { In situ } \\
1 \\
1\end{array}$ & $\begin{array}{c}43-44 \\
40-41 \\
86-88 \\
89 \\
46 \\
48-51,90-91 \\
91\end{array}$ & \begin{tabular}{|c|}
25 \\
21 \\
$17 \cdot 5$ \\
20 \\
39 \\
11,11 \\
24
\end{tabular} & $\begin{array}{l}41-45 \\
39-82 \\
73-94 \\
52-95 \\
43-49 \\
46-99 \\
68-320\end{array}$ & $\begin{array}{l}0 \\
1 \\
0 \\
0 \\
1 \\
0 \\
0\end{array}$ \\
\hline \multicolumn{7}{|c|}{ Poorly Differentiated Cases } \\
\hline $\begin{array}{r}1 \\
2 \\
3 \\
4 \\
5 \\
6 \\
8 \\
9 \\
10 \\
11 \\
18 \\
20 \\
22 \\
23 \\
26 \\
27 \\
28 \\
30\end{array}$ & $\begin{array}{l}35 \\
51 \\
25 \\
12 \\
27 \\
23 \\
24 \\
16 \\
41 \\
29 \\
15 \\
34 \\
29 \\
30 \\
26 \\
21 \\
28 \\
26\end{array}$ & \begin{tabular}{c|}
2 \\
2 \\
2 \\
3 \\
3 \\
3 \\
2 \\
3 \\
Insitu \\
2 \\
3 \\
2 \\
2 \\
2 \\
1 \\
3 \\
2 \\
2
\end{tabular} & \begin{tabular}{|c|}
72 \\
$84-87$ \\
45 \\
$\frac{46}{46}$ \\
62 \\
$\frac{-}{42}$ \\
74 \\
$\overline{70}$ \\
70 \\
$73-74$ \\
70 \\
68 \\
91
\end{tabular} & 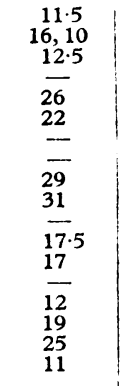 & $\begin{array}{l}37-228 \\
47-146 \\
43-86 \\
44-102 \\
34-47 \\
26-65 \\
26-96 \\
31-115 \\
27-91 \\
51-136 \\
41-108 \\
48-134 \\
40-111 \\
30-87 \\
29-180 \\
44-120 \\
53-76 \\
67-107\end{array}$ & $\begin{array}{r}0 \\
1 \\
0 \\
2 \\
0 \\
0 \\
1 \\
0 \\
7 \\
1 \\
0 \\
7 \\
0 \\
12 \\
1 \\
0 \\
2 \\
3\end{array}$ \\
\hline
\end{tabular}

CASE No.

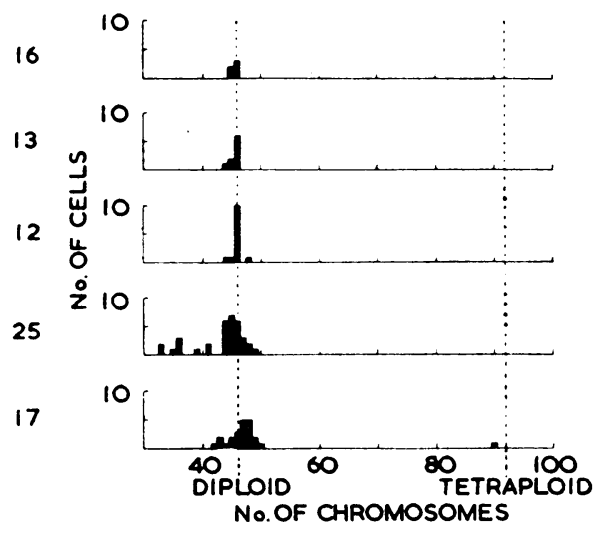

FIG. 1.-Distribution of chromosome counts in well-differentiated transitional-cell carcinoma (five cases). 
five tumours is $54 \%$. Hyperdiploid cells were found in only one of the three tumours with a mode of 46 (Case 12). In the other two tumours (Cases 25 and 17) the spread is more even above and below the modal value. Only one tumour showed invasion (Case 17, modal value 47-48). In none of these five cases did the apparent values of non-countable spreads lie outside the diploid range.

Moderately Well-differentiated Tumours (see Table and Fig. 2).-This histological grade is associated in four tumours with a near tetraploid mode (Cases 15, 19, 24, and 29). One of these (Case 24) shows a bimodal distribution with a near diploid and a near tetraploid mode. Histologically this is a papillary tumour with areas where well-differentiated cells are replaced by larger cells with a less orderly arrangement, giving a gracting of moderately well-differentiated transitional carcinoma. All these four cases show mucosal invasion. The remaining three tumours with modal values near diploid do not show invasion (Cases 7, 14, and 21). As a group, the moderately well-differentiated tumours show a wider range of counts and a lower mean percentage of cells with counts at the modal value $(30 \%)$ compared with the well-differentiated tumours. The apparent values of non-countable spreads showed a variation from the counted values in one case (No. 14) which probably had more cells with counts in the higher range than appears in Fig. 2.

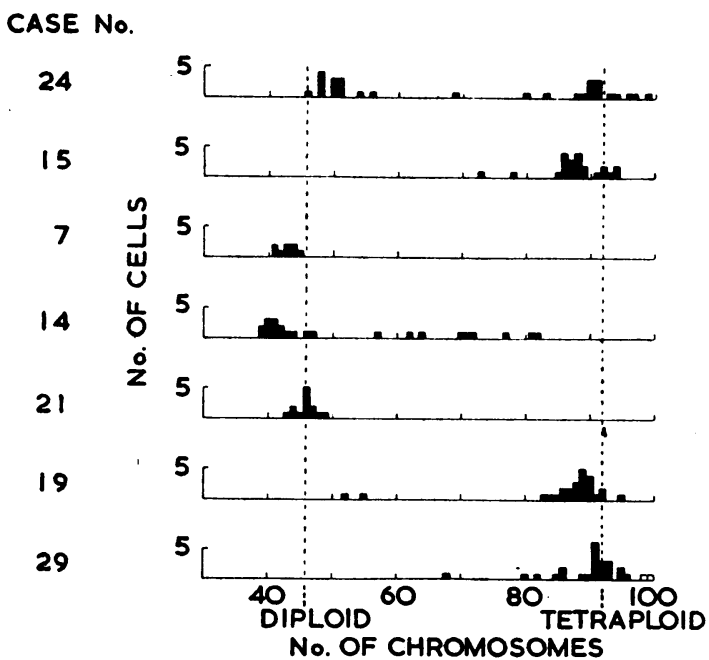

FIG. 2.-Distribution of chromosome counts in moderately well-differentiated transitional-cell carcinomas (7 cases). The open squares indicate cells with chromosome counts of higher than 100 or less than 30 .

Poorly Differentiated Transitional-cell Carcinoma (see Table and Fig. 3).-These cases show a decrease in modal values from near tetraploid to hypotetraploid levels. This change is associated with widening of the range of counts and a fall in the percentage of cells at the modal value. The mean percentage of cells at the modal value for the whole group is $17 \%$. Three cases have near diploid mode (Cases 3, 5, and 10). The results for Case 5 may not belong in the poorly differentiated group, since histologically the region from which chromosome preparations were made included both poorly differentiated invasive tumour and areas of well-differentiated tumour without invasion. Among the 17 poorly differentiated tumours with invasion no correlation could be found between the degree of invasion and either the modal value or the range of counts. Similarly there was no correlation between any particular pattern of chromosome counts and the presence of a completely undifferentiated or anaplastic histological picture (as in Cases 4, 6, 8, 20, and 22). The apparent value of uncountable spreads was not significantly different from the recorded results in any case, although in several cases there were uncountable spreads with very large numbers of chromosomes.

\section{Structural Chromosome Abnormalities}

Detailed karyotyping of chromosome spreads was not carried out in this study. Not all countable spreads were suitable for karyotyping-this was unfortunately true for many of the spreads of the well-differentiated cases with diploid modes. It is not possible to say at this stage whether these cells are true diploids or pseudodiploids.

Obvious chromosome abnormalities recognizable during counting were fairly common, and were recorded (see Table). The abnormalities seen were chromosomes of unusual large size or centromere position, ring forms, dicentrics, and minute double fragments; these last were often multiple, but never formed more than a small percentage of the total chromatin material in the spread. If a similar abnormal chromosome was seen in more than one spread it was thought to be a " marker chromosome."

None of the well-differentiated cases showed structural chromosome abnormalities. Two of the moderately welldifferentiated cases (Nos. 14 and 21) each showed a single spread with an abnormal chromosome. Ten of the 18 poorly differentiated cases had abnormal chromosomes (see Table) and

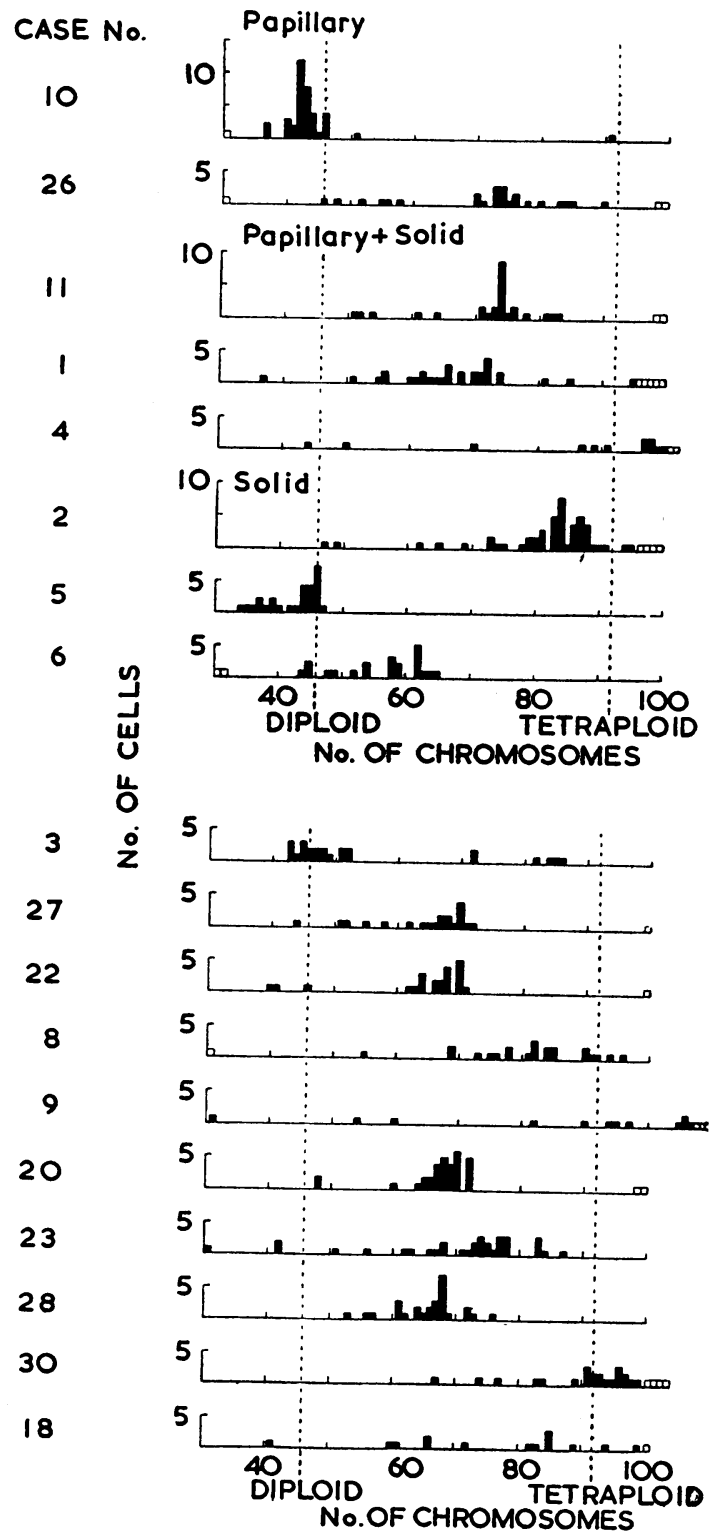

FIG. 3.-Distribution of chromosome counts in poorly differentiated transitional-cell carcinomas (18 cases). The open squares indicate cells with chromosome counts of higher than 100 or less than 30 . 
four of them showed marker chromosomes. Case 23 had the highest incidence, 12 out of 30 spreads having abnormal chromosomes.

\section{Summary of Results}

These results indicate a relationship between chromosome counts and the histological appearance. The more-differentiated tumours have a near diploid modal value. With progressive loss of differentiation the modal value increases to hypotetraploid levels, and in the least-differentiated cases the mode falls to 60-80. Associated with these changes are an increase in chromosome structural abnormalities, a widening of the range of counts, and a decrease in the percentage of counts at the modal value. Thus the mean counts of cells lying at the modal value are $54 \%$ in well-differentiated and $17 \%$ in poorly differentiated tumours.

All the eight non-invasive tumours had near diploid modes. Of the 22 invasive tumours only two had near diploid modes (one of these, Case 5, may not be invasive). This difference between non-invasive and invasive tumours is evident in Fig. 4.

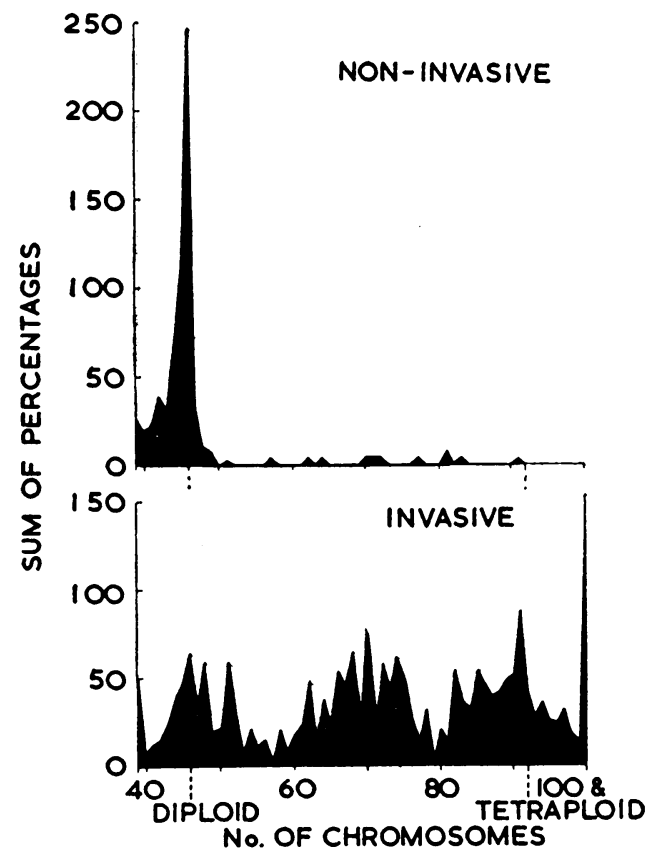

FIG. 4.-Chromosome number of cells from non-invasive bladder tumours (8 cases) compared with invasive bladder tumours (22 cases). Expressed as the sum of the percentage of cells counted from each case.

In the invasive group of tumours those with a moderately well-differentiated histological picture have higher chromosome counts than most of the poorly differentiated ones. The presence of a near diploid mode seems to relate more to an absence of invasion than to a well-differentiated histological picture.

\section{Discussion}

\section{Chromosome Changes in Malignancy}

In contrast to the constancy of the diploid karyotype in normal tissues (Hauschka, 1963) primary malignant tumours in man show a wide range of chromosome counts and karyotypic abnormalities (Makino et al., 1959, 1964 ; Hauschka, 1961 ; Spriggs, 1964).

The pattern of chromosome counts described in the literature has been similar to the present finding in that a stem line with a modal value and a scatter of counts above and below it was present in most. However, the modal value in different tumours has ranged from hypodiploid to hypertetraploid. The results from this study conform to the general pattern of counts described, with the exception of the four poorly differentiated cases which had no definite mode. Similar cases of marked aneuploidy without a definite mide have been described by Makino et al. (1964) in gastric carcinoma, and by Atkin (1964) in adenoacanthomata of the cervix.

\section{Mechanism of Development of Abnormal Chromosome Numbers}

In the poorly differentiated tumours the frequency of hypotetraploid modal values is striking. Hsu et al. (1961), in a study of the chromosome constitution of mouse tumnurs, suggested two pathways for the production of a hypoteraploid mode: (1) Diploid $\rightarrow$ tetraploid $\rightarrow$ hypotetraploid ; and (2) Diploid $\rightarrow$ hyperdiploid $\rightarrow$ hypotetraploid.

Lubs and Clark (1963) and Makino et al. (1964) discuss this problem in relation to human material, and both favour the first suggestion of a doubling to a near tetraploid number and the subsequent loss of chromosome to give a hypotetraploid mode. The results in this study agree with this, in particular Case 24, which showed a bimodal distribution of counts with values near diploid and near tetraploid. The chromosome counts are closely related to the histological picture, and it seems unlikely that progression of chromosome counts from near diploid to hypotetraploid, with associated redifferentiation of the tumour from poorly differentiated to moderately well-differentiated, would occur.

\section{Correlation of Chromosome Counts with Histological Picture}

In this group of bladder tumours there is a close correlation between the chromosome counts and the histological picture. Such a close correlation has not been previously reported for tumours at other sites. Shigematsu (1965) performed chromosome counts on a series of bladder tumours; the series includes all types of bladder tumours; the histological grading and the grading of invasion differ from those used in this series. Though not truly comparable with this series, the results agree with the general trend: non-invasive tumours had near diploid nodes, while less well-differentiated invasive cases had counts which fell away from the tetraploid level.

Atkin (1964) found that there was a relationship between tetraploid levels of D.N.A. in nuclei of adenocarcinomas of both uterine body and cervix and the presence of an anaplastic histological picture, but found no such correlation for squamous carcinoma of the cervix. Makino et al. (1959, 1964), Hauschka (1961), and Spriggs et al., 1962b) could find no correlation between the histopathological picture and their chromosome counts of karyotypic abnormalities in a selection of human primary tumours and malignant effusions. There is no evidence that chromosome counts derived from malignant effusions mirror the situation at the primary site ; on the contrary, there is evidence that they may differ (Ishihara et al., 1963 ; Makino et al., 1964). These large series consisted of tumours from a variety of primary sites, and there has been a tendency to look for correlations common to tumours from different sites.

The results from this series, compared with those of Atkin (1964) for squamous carcinoma of the cervix, suggest that correlation between the histopathology and chromosome count does occur-but in a fashion characteristic for any given type of tumour.

\section{Correlation of Chromosome Counts with Invasion}

Non-invasive bladder tumours in this series have near diploid modal values, and invasion is associated with a near tetraploid 
or hypotetraploid modal value. However, there is no relationship between the depth of invasion and the pattern or level of chromosome counts for any histological grade. The known difference in prognosis for bladder tumours associated with different degrees of invasion does not seem to relate to the chromosomal finding. The larger plump-looking nuclei of cells with tetraploid modes can be recognized in histological sections (as in Case 24). This may be of value in the histological assessment of biopsies-apparent absence of invasion in presence of such large cells should be viewed with suspicion.

In the study of squamous carcinoma of the cervix Atkin (1962) and Atkin and Richards (1964) could find no relationship between either D.N.A. levels or chromosome counts with depth of invasion. However, they suggested that the better prognosis in those cases with hypotetraploid modal values may be associated with a reduced tendency for lymphatic spread. This aspect of the histopathological picture has not been dealt with by other workers.

It has been shown for the uterine cervix that non-invasive, premalignant lesions may present abnormalities of chromosome number of karotype (Spriggs et al., 1962a ; Boddington et al., 1965 ; Wakonig-Vaartaja and Hughes, 1965). WakonigVaartaja and Hughes (1965) found that the most marked chromosome changes occur between dysplasia (with counts around diploid) and carcinoma-in-situ (more marked aneuploidy and with the majority of counts lying between 75 and 95). No difference was noted between the chromosome changes in carcinoma-in-situ and truly invasive carcinoma. However, on taking a further 11 cases into consideration, Kirkland (1966) concluded that a difference in chromosome-number distribution between carcinoma-in-situ and carcinoma of the cervix was just perceptible statistically.

In this series of bladder tumours the most abrupt change in chromosome number occurs in association with invasion (see Fig. 4, which summarizes the chromosome-number distributions for all the cases studied). It should be noted that the karyotype of the diploid cells in this series is not known; pseudodiploid cells from tumours have been reported (Ishihara and Sandberg, 1963 ; Spriggs, 1964).

\section{Correlation of Chromosome Counts with Prognosis}

There is evidence that for some types of malignancy prognosis may be related to chromosome number. Atkin and Richards (1962) and Atkin (1964) have shown that there is a correlation between both D.N.A. levels and chromosome counts and prognosis in squamous carcinoma of the cervix, but not in cases of adenocarcinoma of the cervix or body of uterus. In squamous carcinoma of the cervix those with hypotetraploid modal values have a better prognosis than those with near tetraploid modes, and both these have a better prognosis compared with cases having near diploid modes.

The present series of patients with transitional-cell tumours of the bladder has been followed up for only one to two years -which is too short a time for adequate follow-up. It is accepted that whatever the classification used there is a close relationship between both loss of differentiation and depth of invasion and prognosis (Jewett and Strong, 1946; Frankson, 1950 ; Prout and Marshall, 1956 ; Pugh, 1959 ; Payne, 1959). Thus one would expect the poorly differentiated cases with T2 and T3 invasion to have a worse prognosis than moderately differentiated cases with $\mathrm{T} 1$ invasion. In turn, all the invasive cases would have a worse prognosis than the non-invasive cases in the well-differentiated and moderately differentiated groups. Expressed in terms of chromosome counts, the best prognosis in transitional-cell carcinomas of the bladder is among the near diploid, and the worst among the cases with hypotetraploid modes. This is the reverse of the findings of Atkin for squamous carcinoma of the cervix.

\section{Histological Classification of Bladder Tumours}

There is no universally accepted classification of transitionalcell carcinomas of the bladder (Frankson, 1950 ; Pugh, 1959). The histological classification of bladder tumours used in this paper is one with a strong clinical bias. The histological appearances are interpreted in the light of known clinical associations and long-term follow-up of similar tumours. Such a statistical basis may not adequately separate the natural history of a single tumour from that of the whole bladder epithelium, with its known propensity for multiple tumour production. It is exceptional for tumours at other sites to be called carcinoma on histological grounds in the absence of any evidence of invasion, as occurs with this classification. That there is a fairly constant chromosome pattern associated with the onset of invasion suggests that there is a basic difference between the non-invasive and the invasive tumours. On these grounds a classification of bladder tumours, placing more emphasis on the presence or absence of invasion-such as that of Franksson (1950)-may be preferable to the one used in this study, which is based mainly on alterations in cellular and tissue differentiation.

\section{Summary}

This study describes the chromosome counts and the histological features of 30 transitional-cell carcinomas of the bladder.

With progressive loss of cellular differentiation there is first (1) an increase and then a decrease in chromosome number, (2) a wider range of chromosome numbers, and (3) an increase in chromosome structural abnormalities. The appearance of invasion is related more closely to an increase in the chromosome count than to loss of cellular differentiation. The results are discussed in the light of the chromosome finding for solid tumours at other sites.

The bladder tumours for this study were provided by Mr. D. M. Wallace, of the Royal Marsden Hospital, without whose enthusiasm this survey would not have been made. Dr. N. F. C. Gowing kindly gave me access to slides and specimens of some cases. The technique for making chromosome preparations from solid tumours was developed while working in the Department of Clinical Pathology at the Bristol Royal Infirmary, where Mr. Ashton Miller provided the samples of bladder tumour. I would like to thank Dr. Lynne Reid for her encouragement and for allowing me to continue this work in her department. Miss Jean Waldron drew the graph and the histograms. This work was performed while in receipt of a grant from the Medical Research Council.

\section{REFERENCES}

Atkin, N. B. (1964). Brit. F. Radiol., 37, 213.

and Richards, B. M. (1962). Brit. med. F., 2, 1445

Boddington, M. M., Spriggs, A. I., and Wolfendale, M. R. (1965). Ibid., $1,154$.

Dukes, C. E. (1959). In Tumours of the Bladder, edited by D. M. Franksson, C. (1950). Acta chir. scand. Surgh and London.

Hauschka, T. S. (1961). Cancer Res., 21, 957.

(1963). Exp. Cell Res., Suppl. No. 9, 9.86

Hsu, T. C., Billen, D., and Levan, A. (1961). Э. nat. Cancer Inst., 27,

shihara, T., Kikuchi, Y., and Sanaberg, A. A. (1963). Ibid., 30, 1303. and Sandberg, A. A. (1963). Cancer (Philad.), 16, 885. Jewett, H. J., and Strong, G. H. (1946). F. Urol. (Baltimore), 55, 366. Kirkland, J. A. (1966), Lancet, 1, 152.

Lubs, H. A., and Clark, R. (1963). New Engl. ₹. Med., 268, 907. 184. S., Ishihara, T., and Tonomura, A. (1959). Z. Krebsforsch., 63, 184.

741. 741.

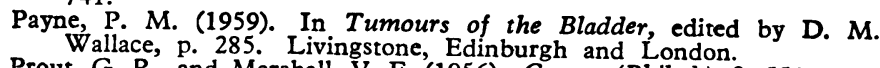

Prout, G. R., and Marshall, V. F. (1956). Cancer (Philad.), 9, 551.

Pugh, R. C. B. (1959). In Tumours of the Bladder, edited by D. M. Wallace, p. 116. Livingstone, Edinburgh and London.

Spriggs, A. I. (1964). Brit. F. Rudiol., 37, 210.

Boddington, M. M., and Clarke, C. M. (1962a). Lancet, 1, 1383. Shige - (1962b). Brit. med. f., 2, 1431

gematsu, S., "Significance of the Chromosome in Vesical Cancer," Reports of the XIII Congress of the Sociéte Internationale d'Urologie, 1965, 2, 111. Livingstone, London.

Wakonig-Vaartaja, R., and Hugkes, D. T. (1965). Lancet, 2, 756. 